\title{
Erratum to: Control of Two-Photon Transport in a One-Dimensional Waveguide
}

\author{
Wei-Bin Yan · Zhong-Ju Liu • Ling Zhou
}

Published online: 13 October 2012

(C) Springer Science+Business Media New York 2012

Erratum to: Int J Theor Phys (2012) 51:2237-2245

DOI 10.1007/s10773-012-1103-0

The original version of this article unfortunately contained one mistake. Figure 3(b) was incorrect. Corrected version of Fig. 3(b) is given below:

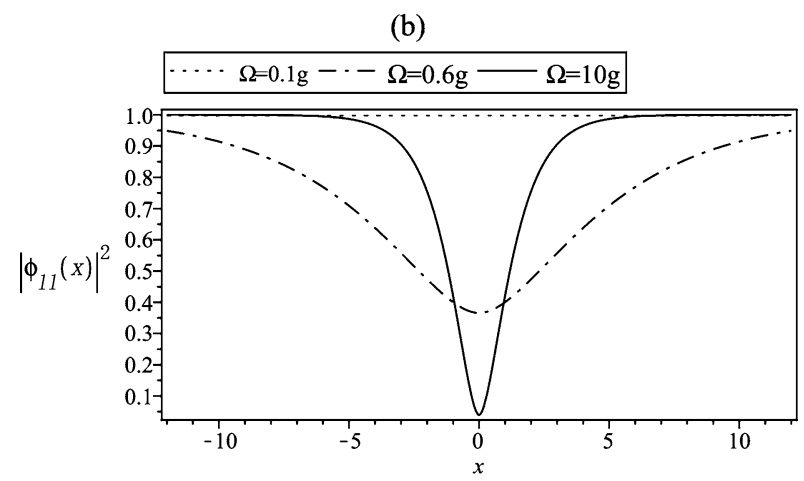

The online version of the original article can be found under doi:10.1007/s10773-012-1103-0.

W.-B. Yan · Z.-J. Liu · L. Zhou ( $\bowtie)$

School of Physics and Optoelectronic Technology, Dalian University of Technology, Dalian 116024,

P.R. China

e-mail: zhlhxn@dlut.edu.cn

W.-B. Yan

e-mail: yanweibin1983@163.com 